\title{
Haploid Induction in Hull-less Seed Pumpkin through Parthenogenesis Induced by X-ray-irradiated Pollen
}

\author{
Kristina Košmrlj, Jana Murovec, and Borut Bohanec ${ }^{1}$ \\ Agronomy Department, Biotechnical Faculty, University of Ljubljana, Jamnikarjeva 101, \\ 1000 Ljubljana, Slovenia
}

\begin{abstract}
AdDitional Index words. Cucurbita pepo ssp. pepo var. styriaca, irradiation dose, female parent, pollen donor, flow cytometry, SSR markers

Abstract. Production of hull-less seeds of styrian oil pumpkin (Cucurbita pepo ssp. pepo var. styriaca) is increasing as a result of demand for aromatic seed oil and for other uses. Hybrid cultivars have recently been released but a method for haploid induction has not been established. We focused on the development of a parthenogenetic haploid induction protocol based on pollination with pollen irradiated with $X$-ray radiation at $0,50,100,150,200,300$, and $350 \mathrm{~Gy}$. Fruit set largely decreased at $200 \mathrm{~Gy}$, whereas a decline in embryo formation was observed at $100 \mathrm{~Gy}$. Various accessions were tested as the female parent or as the pollen donor and large differences were found. The best parthenogenetic response was found in 'Turkey \#2' $(10.0 \%)$, 'Gleisdorfer Ölkürbis' $(4.4 \%)$, and 'Naked Seed' $(3.9 \%)$, whereas 'GL Opal' and 'White Acorn' were efficient as pollen donors. The ploidy level of 3830 putative parthenogenetic embryos was determined using flow cytometry. Four ploidy levels (n, $2 n, 3 n$, and $4 n$ ) were found with the majority being diploid. Interestingly, a significant proportion was determined to be tetraploid and this was clearly correlated with increased radiation delivered to pollen grains. Using selected simple sequence repeat markers on diploid embryos, no spontaneous chromosome doubling could be confirmed. In this study, haploid induction in styrian oil pumpkin was elaborated for the first time. We also showed that $\mathrm{X}$-ray pollen irradiation provides an alternative to gamma radiation treatment, yielding a sufficient percentage of haploid plantlets.
\end{abstract}

As a result of ever greater interest in the hull-less seeds of styrian oil pumpkin for oil production or roasted snacks in central Europe and elsewhere, new biotechnological methods are needed to accelerate breeding programs and offer producers modern cultivars with outstanding characteristics such as high yield, disease resistance, bush growth habit, and uniformity. The most recently released cultivars are hybrids, so the development of an efficient haploid induction protocol for creating homozygous lines is highly desirable. Inbreeding depression is well known in cucurbits (Cardoso, 2004; Stephenson et al., 2001). In addition, selection on the haploid level and the regeneration process per se might also exclude embryos possessing deleterious mutations.

Reliable protocols for haploid induction based on in situ parthenogenetic haploid induction by irradiated pollen have been published for some species of Cucurbitaceae. Obtaining haploids by in vitro rescue of parthenogenetic melon (Cucumis melo) embryos induced by pollination with irradiated pollen (Sauton and Dumas De Vaulx, 1987) was the first reported success in cucurbit crops. Three studies have been published on the genus Cucurbita. The authors used gamma ray pollen irradiation followed by in vitro culture of immature embryos (Kurtar and Balkaya, 2010; Kurtar et al., 2002, 2009). In these studies, season, maternal genotype, irradiation dose, embryo stage, and embryo type (necrotic vs. normal) are reported to be the main factors that affect haploid induction. Tested doses ranged between 25 and 400 Gy with the optimum found to be

Received for publication 17 Apr. 2013. Accepted for publication 30 May 2013. This work was supported by the Slovenian Research Agency grant numbers P40077 and 1000-10-310191.

${ }^{1}$ Corresponding author. E-mail: borut.bohanec@bf.uni-lj.si. below 100 Gy. Confirmation of the ploidy level of regenerants was well described by chromosome counting, stomata and chloroplast observations, and morphological observations of plants. An irradiated pollen approach has also been found to be successful in related species such as melon (Godbole and Murthy, 2012; Gonzalo et al., 2011; Sauton and Dumas De Vaulx, 1987), cucumber [Cucumis sativus (Claveria et al., 2005; Przyborowski and Niemirowicz-Szczytt, 1994)], and watermelon [Citrullus lanatus (Sari et al., 1994)]. The gamma ray doses used in the related species were generally higher (200 to $500 \mathrm{~Gy})$. In addition to gamma rays, ultraviolet irradiation and $\mathrm{X}$-rays have also been used for in situ haploid induction. X-rays have proved to be efficient in melon (Katoh et al., 1993), carnation [Dianthus caryophyllus (Sato et al., 2000)], and pummelo [Citrus maxima (Yahata et al., 2010)].

The present study was designed to measure the effect of $\mathrm{X}$-ray pollen irradiation on fruit set and embryo formation, and both irradiation dose and parental genotype on haploid embryo induction. Large-scale flow cytometric determination of ploidy level and an optimized protocol for simple sequence repeat (SSR) marker analysis were used to carefully examine the ploidy and homozygosity of obtained embryos.

\section{Materials and Methods}

Plant material and POllination with iRRadiated POLlen. A total of 13 accessions (Table 1) were used in experiments conducted in 2011 and 2012. Plants were grown in spring and summer in greenhouse and open-field conditions managed using standard agronomic practices. Male and female flowers were isolated $1 \mathrm{~d}$ before opening as shown in Figure 1A to avoid undesirable crosses. The next morning anthers were collected, 
Table 1. List of Cucurbita accessions used as female parent and/or pollen donor in haploid induction experiments in 2011 and 2012.

\begin{tabular}{lclll}
\hline Species & Accession no. & \multicolumn{1}{c}{ Accession name } & Accession type & Provider $^{\mathrm{y}}$ \\
\hline C. pepo & $/$ & Gleisdorfer Ölkürbis $^{\mathrm{z}}$ & Cultivar & Saatzucht Gleisdorf, Austria \\
& $/$ & GL Opal $^{\mathrm{z}}$ & Hybrid & Saatzucht Gleisdorf, Austria \\
& $/$ & GL Maximal $^{\mathrm{z}}$ & Hybrid & Saatzucht Gleisdorf, Austria \\
& $/$ & Gleisdorfer Diamant $^{\mathrm{z}}$ & Hybrid & Saatzucht Gleisdorf, Austria \\
& $/$ & Beppo $^{\mathrm{z}}$ & Hybrid & Saatbau Linz, Austria \\
& $/$ & Elite F1 & Slovenska golica & Semenarna Ljubljana, Slovenia \\
& $/$ & Rumena golica & Sybrid & Semenarna Ljubljana, Slovenia \\
& PI 267664 & Yellow Long & Cultivar Ivančič, UniMB, Slovenia & USDA \\
PI 420329 & Turkey \#2 & Breeding line & USDA \\
C. moschata & PI 615102 & Naked Seed & Uncertain & USDA \\
\hline
\end{tabular}

${ }^{\mathrm{z} H u l l-l e s s}$ accession.

${ }^{y}$ UniMB = University of Maribor, Faculty of Agriculture and Life Sciences; USDA = U.S. Department of Agriculture.

placed in petri dishes, and irradiated at different doses using an X-ray unit (RX-650; Faxitron Bioptics, Tucson, AZ). Female flowers were pollinated immediately after irradiation (from 0600 to $1030 \mathrm{HR}$ ) and re-isolated.

IN VITRO EMBRYO CULTURE. Immature fruit were harvested $\approx 4$ weeks after pollination and cleaned under tap water. Seeds were extracted, surface-sterilized for $20 \mathrm{~min}$ using dichloroisocyanuric acid sodium salt (Acros Organics, Geel, Belgium) in a $2 \%$ solution $(\mathrm{w} / \mathrm{v})$ with Tween 20 (Sigma-Aldrich, St. Louis, MO) added as a surfactant, washed with sterilized water over a sterile stainless steel mesh, and opened aseptically in a laminar flow hood. The excised embryos were cultured on solid E20A medium (Sauton and Dumas De Vaulx, 1987) in 100-mm square petri dishes with 25 compartments (Sterilin, Newport, U.K.) at $23{ }^{\circ} \mathrm{C}$ with a $16-\mathrm{h}$ photoperiod (Fig. 1B).

DeTERmination OF PLOIDY LEVEL AND HOMOZYGOSITY TESTING. Ploidy level was determined by flow cytometry using 4',6'-diamidino-2-phenylindole (Partec, Görlitz, Germany) staining according to Bohanec (2003). Measurements were done on a CyFlow space flow cytometer (Partec) using a linear scale with a diploid $C$. pepo plant positioned at channel 200 as an external standard.

Total genomic DNA was extracted from fresh leaves of the parental plants and cotyledonary or leaf tissue of the cultured embryos using a modified cetyl trimethylammonium bromide extraction method (Kump and Javornik, 1996). Extracted DNA was resuspended in Tris-EDTA, DNA concentration was quantified by fluorimetry (Hoefer DyNA Quant 200; GE Healthcare, Little Chalfont, U.K.), and a dilution at a concentration of $5 \mathrm{ng} \cdot \mu \mathrm{L}^{-1}$ was used as a template for polymerase chain reaction (PCR) amplification. Published SSR markers (Gong et al., 2008) were used to test possible homozygosity caused by spontaneous chromosome doubling. The total volume of the PCR mixture was $15 \mu \mathrm{L}$ with $25 \mathrm{ng}$ of genomic DNA, 0.5 U Taq DNA polymerase (Promega, Madison, WI), $0.2 \mathrm{~mm}$ of each dNTP (Sigma-Aldrich), $1 \times$ PCR buffer, $2 \mathrm{~mm} \mathrm{MgCl}_{2}$ (Promega), $0.2 \mu \mathrm{M}$ of each primer, and $0.25 \mu \mathrm{M}$ dye-labeled primer (6-FAM, VIC, NED, or PET; Applied Biosystems, Foster City, CA). Forward primers were designed with an M13 tail sequence added to their $5^{\prime}$ end (5'-TGTAAAACGACGGCCAGT-3'). Amplification of SSRs with touchdown PCR was performed according to Formisano et al. (2012). PCR products were analyzed by capillary electrophoresis (3130xl Genetic Analyzer; Applied Biosystems) with GeneScan ${ }^{\mathrm{TM}} 600$ LIZ $^{\circledR}$ (Applied Biosystems) as an internal size standard. The allele sizes were analyzed with Peak Scanner software (Version 1.0; Applied Biosystems).

\section{Results}

EFFECT OF DIFFERENT IRRADIATION DOSES ON FRUIT SET, MEAN EMBRYO NUMBER, AND HAPLOID EMBRYO INDUCTION. Optimization of a haploid induction protocol was tested in 2 consecutive years (2011 and 2012). Data were recorded for fruit set, mean embryo number per 100 seeds, and ploidy level of regenerated embryos. To test the effect of the irradiation dose on fruit set and embryo formation, 'Gleisdorfer Ölkürbis' was pollinated with pollen of 'GL Opal' irradiated at 0, 50, 100, 150, 200, 300, and 350 Gy (Table 2). In a control treatment (pollination with non-irradiated pollen), fruit set and mean number of embryos per 100 seeds were $55.6 \%$ and 73.4 , respectively. A gradual decrease of both parameters was observed at increased irradiation doses. At the highest irradiation dose (350 Gy), fruit set and mean number of embryos was $25.0 \%$ and 18.8 , respectively. In the next year (2012), the response to the most effective doses in terms of haploid induction $(100,200$, and $300 \mathrm{~Gy})$ was repeated. The ploidy level of in vitro-grown plantlets obtained in 2011 and 2012 is shown in Table 3. The results showed that the ploidy level of plantlets was haploid, diploid, triploid, or tetraploid. In both years, the highest proportion of haploids $(4.4 \%$ in 2011 , $1.1 \%$ in 2012) was found at $200 \mathrm{~Gy}$, although the success of haploid induction was lower in 2012. Of 1397 plantlets analyzed, 12 were haploid, 1376 diploid, one triploid, and eight were tetraploid. Figures $2 \mathrm{~A}$ and $2 \mathrm{~B}$ show typical histograms of diploid and haploid embryos, respectively, whereas an example of a haploid sample revealing extensive endoreduplication is given in Figure 2C.

EFFECT OF FEMALE PARENT ON HAPLOID EMBRYO INDUCTION. Seven accessions ('Beppo', 'Rumena golica', 'Slovenska golica', 'Turkey \#2', 'Naked Seed', 'Gleisdorfer Diamant', and 'GL Maximal') were used to evaluate whether the genetic constitution of the female parent affects the success of haploid embryo induction. Pollen of 'GL Opal' was irradiated at 200 and 300 Gy and used for pollination. Fruit set and embryo formation were observed in all tested accessions. In 2011, haploid embryos were 

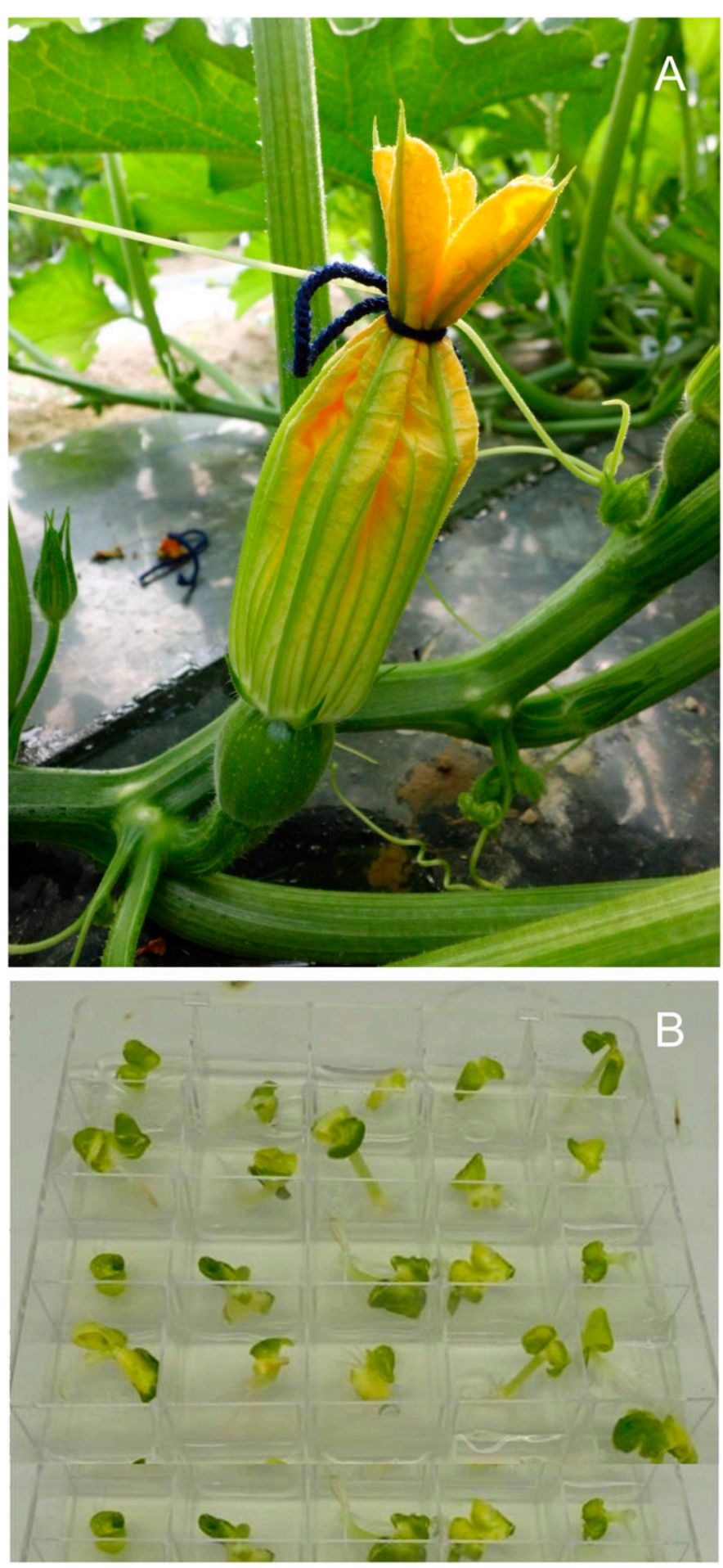

Fig. 1. Haploid induction in hull-less pumpkin. (A) Isolation of female flowers to avoid cross-pollination. (B) In vitro culture of rescued embryos on solid E20A medium (Sauton and Dumas De Vaulx, 1987).

obtained in all tested accessions except 'Slovenska golica', in which one treatment was lost as a result of contamination. The observed percentages of haploid embryos ranged from $0 \%$ in 'Rumena golica' and 'Naked Seed' to $10 \%$ in 'Turkey \#2' for pollen irradiated at $200 \mathrm{~Gy}$ and from $0 \%$ in 'Slovenska golica' to $3.9 \%$ in 'Naked Seed' for pollen irradiated at 300 Gy (Table 4). In 2012, haploids were obtained only from 'GL Maximal', whereas 'Gleisdorfer Diamant' was not responsive in this year. Ploidy level was determined for a total of 1586 in vitro-grown plantlets. The plantlets were predominantly diploid (1549), 15 were haploid, one triploid, and 21 tetraploid. Generally, more tetraploids were found at higher irradiation doses.

EFFECT OF POLLEN DONOR ON HAPLOID EMBRYO INDUCTION. In 2012, pollen from five accessions ('Yellow Long', 'White Acorn', 'Elite F1', 'GL Maximal', and 'Muscade de Provence') were irradiated at 200 and 300 Gy and used for pollination of 'GL Opal' to evaluate the effect of the pollen donor on haploid embryo induction. One haploid was obtained when pollination was carried out with 'White Acorn' pollen irradiated at $300 \mathrm{~Gy}$. No fruit set was observed after pollination with pollen of 'Yellow Long' irradiated at 300 Gy and 'Muscade de Provence' (cultivar of Cucurbita moschata) at 200 and 300 Gy (Table 5). Ploidy level was determined for a total of 847 samples, of which one was haploid, 818 diploid, and 28 tetraploid.

HoMOzYgosity TESTING OF DIPLOID PLANTLETS. For reliable testing of homo/heterozygosity, 23 published SSR markers (data not shown) were tested and six (CMTp80, CMTp88, CMTp125, CMTp142, CMTp235, and CMTp245) amplifying multiple discrete alleles were chosen for further analysis. Molecular analysis was performed on 253 diploids obtained from fruit of 'Gleisdorfer Ölkürbis', 'Beppo', and 'Turkey \#2' pollinated with irradiated 'GL Opal' pollen, in which haploids were found. A list of observed SSR allele lengths at the given loci is given in Table 6. For each cross combination, an appropriate primer set was chosen based on the allelic constitution of the female parent and pollen donor. Each embryo was analyzed at least at two loci at which the pollen donor plant had at least one allele different from the female parent. To distinguish between diploids of zygotic origin and spontaneously doubled haploids (DHs), their allelic constitution was compared with the allelic constitution of parental plants; $245(96.8 \%)$ samples showed heterozygosity at the first two loci tested, whereas eight were homozygous at both tested loci. Heterozygosity was confirmed for seven by testing an additional locus, thereby allowing $99.6 \%$ of tested samples to be confirmed as heterozygous. A single individual tested at four loci could not be determined as heterozygous but its homozygosity and thereby spontaneous chromosome doubling could also not be confirmed as a result of a lack of a completely distinct allele pattern of the parental plants. In four samples determined as heterozygous, the absence of the paternal allele was detected in one locus.

\section{Discussion}

In 'Gleisdorfer Ölkürbis', fruit set was observed at all tested irradiation doses. No fruit set was observed when 'GL Opal' was pollinated with 'Yellow Long' pollen irradiated at 300 Gy or after pollination with 'Muscade de Provence' (C. moschata). Although interspecific hybridization between $C$. реро $\times$ C. moschata has been previously reported (Šiško et al., 2003), interspecific pollination with irradiated pollen did not induce fruit formation. For all other combinations, at least some pollinations resulted in fruit formation. Although increased $\mathrm{X}$-ray doses affected the formation of embryos, some were formed even at the highest radiation treatment. These findings are in contrast with published results in C. pepo (Kurtar et al., 2002 ), in which fruit set was achieved at gamma ray doses up to $400 \mathrm{~Gy}$, but no embryos were formed at doses higher than $50 \mathrm{~Gy}$. However, a general decrease of both parameters was 
Table 2. Effect of irradiation dose on fruit set and mean number of embryos per 100 seeds using hull-less pumpkin accessions 'GL Opal' as a pollen donor and 'Gleisdorfer Ölkürbis' as a female parent, tested in 2011.

\begin{tabular}{lcccc}
\hline & $\begin{array}{c}\text { Flowers } \\
\text { Irradiation } \\
\text { pollinated } \\
\text { dose (Gy) }\end{array}$ & $\begin{array}{c}\text { Fruit } \\
\text { set (\%) }\end{array}$ & $\begin{array}{c}\text { Fruit used } \\
\text { for MNE } \\
\text { determination } \\
\text { (no.) }\end{array}$ & $\begin{array}{c}\text { MNE [mean } \pm \text { SD } \\
\text { (embryos/100 } \\
\text { seeds) }]\end{array}$ \\
\hline 0 & 9 & 55.6 & 5 & $73.4 \pm 23.8$ \\
50 & 9 & 55.6 & 5 & $64.1 \pm 5.7$ \\
100 & 11 & 45.5 & 5 & $30.7 \pm 7.3$ \\
150 & 10 & 60.0 & 5 & $31.2 \pm 14.6$ \\
200 & 15 & 20.0 & 1 & $27.4^{\mathrm{y}}$ \\
300 & 9 & 33.3 & 3 & $14.8 \pm 2.9$ \\
350 & 8 & 25.0 & 1 & $18.8^{\mathrm{y}}$ \\
\hline
\end{tabular}

${ }^{\mathrm{z}} \mathrm{MNE}=$ mean number of embryos per 100 seeds.

${ }^{\mathrm{y}} \mathrm{SD}$ could not be determined.

Table 3. Effect of irradiation dose on haploid induction using hull-less pumpkin accessions 'GL Opal' as a pollen donor and 'Gleisdorfer Ölkürbis' as a female parent.

\begin{tabular}{lccllll}
\hline & & \multirow{2}{*}{$\begin{array}{c}\text { Embryos } \\
\text { Yith ploidy }\end{array}$} & \multicolumn{4}{c}{ Ploidy level (\%) } \\
\cline { 5 - 7 } Yr & $\begin{array}{c}\text { Irradiation } \\
\text { dose (Gy) }\end{array}$ & determined (no.) & $\mathrm{n}$ & $2 \mathrm{n}$ & $3 \mathrm{n}$ & $4 \mathrm{n}$ \\
\hline 2011 & 50 & 251 & 0.4 & 99.6 & 0 & 0 \\
& 100 & 208 & 1.0 & 99.0 & 0 & 0 \\
& 150 & 357 & 0 & 99.4 & 0.3 & 0.3 \\
& 200 & 113 & 4.4 & 95.6 & 0 & 0 \\
& 300 & 85 & 2.4 & 97.6 & 0 & 0 \\
& 350 & 53 & 0 & 98.1 & 0 & 1.9 \\
& 100 & 37 & 0 & 100 & 0 & 0 \\
& 200 & 175 & 1.1 & 97.1 & 0 & 1.7 \\
& 300 & 118 & 0 & 97.5 & 0 & 2.5 \\
\hline
\end{tabular}

also observed at higher doses of radiation. A different situation was reported in X-ray treatment of watermelon pollen (Sugiyama and Morishita, 2000), in which fruit set was unaffected at $800 \mathrm{~Gy}$, but the number of normal seeds was significantly reduced.

In 2011, most accessions tested as female parents responded positively to haploid induction by induced parthenogenesis, whereas in 2012, haploid induction rates were generally lower. A comparison is given in the case of 'Gleisdorfer Ölkürbis' and 'Gleisdorfer Diamant', which were used as female parents in both years. Lower or no response to the haploid induction treatments was observed in 2012. This variation between years can probably be attributed to weather conditions. According to data provided by the Ministry of the Environment and Spatial Planning, Environmental Agency of the Republic of Slovenia, days with maximum daily temperature of at least $30^{\circ} \mathrm{C}$ occurred more often in 2012. To the best of our knowledge, there are no published studies comparing haploid induction protocol efficiencies in Cucurbita species for 2 consecutive years but differences in haploid induction have been found even within one growing season (Kurtar and Balkaya, 2010; Kurtar et al., 2009).

Within Cucurbitaceae, studies using both gamma (Godbole and Murthy, 2012; Gonzalo et al., 2011; Sauton and Dumas De Vaulx, 1987) and X-ray (Katoh et al., 1993) pollen irradiation are available only for melon, in which applied X-ray doses (1000 Gy) were at least twice as high as gamma ray irradiation (up to $500 \mathrm{~Gy}$ ). In the genus Cucurbita, only gamma rays have
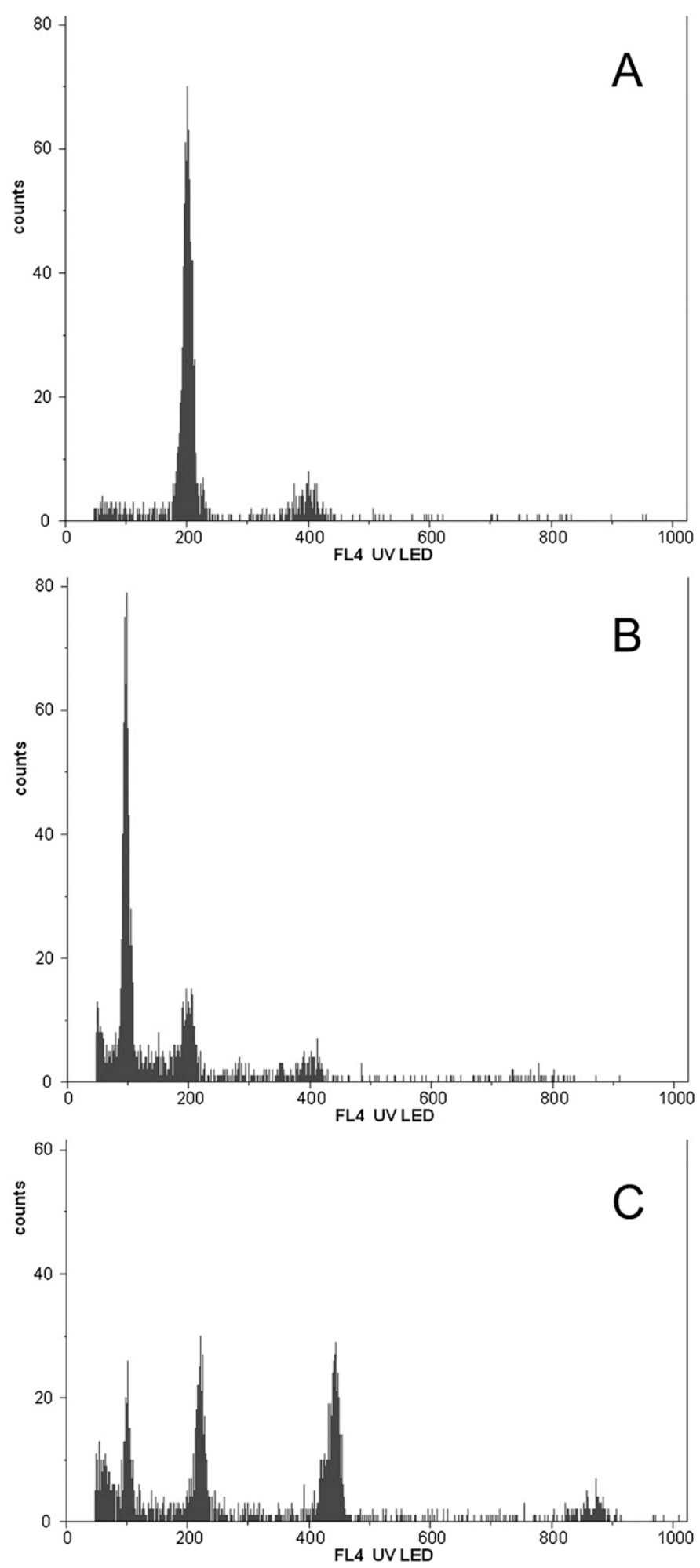

Fig. 2. Flow cytometric ploidy determination of regenerated pumpkin embryos. $4^{\prime}, 6^{\prime}$-diamidino-2-phenylindole fluorescence of nuclei (x-axis) vs. number of nuclei counted (y-axis) in (A) diploid, (B) haploid, and (C) haploid showing extensive endoreduplication.

so far been used and haploids were obtained only up to $100 \mathrm{~Gy}$ (Kurtar and Balkaya, 2010; Kurtar et al., 2002, 2009). These reports might be comparable to our results, in which different $\mathrm{X}$-ray doses led to successful haploid embryo induction with 200 Gy being the most effective for 'Gleisdorfer Ölkürbis', 
Table 4. Comparison of haploid induction efficiencies when using different hull-less pumpkin accessions as a female parent and 'GL Opal' as a pollen donor.

\begin{tabular}{|c|c|c|c|c|c|c|c|}
\hline \multirow[b]{2}{*}{ Yr } & \multirow[b]{2}{*}{ Female parent } & \multirow[b]{2}{*}{ Irradiation dose (Gy) } & \multirow[b]{2}{*}{ Embryos with ploidy determined (no.) } & \multicolumn{4}{|c|}{ Ploidy level (\%) } \\
\hline & & & & $\mathrm{n}$ & $2 n$ & $3 n$ & $4 \mathrm{n}$ \\
\hline \multirow[t]{12}{*}{2011} & Beppo & 200 & 114 & 0.9 & 99.1 & 0 & 0 \\
\hline & & 300 & 80 & 2.5 & 95 & 1.3 & 1.3 \\
\hline & Gleisdorfer Diamant & 200 & 124 & 2.4 & 96.8 & 0 & 0.8 \\
\hline & & 300 & 84 & 1.2 & 98.8 & 0 & 0 \\
\hline & Naked Seed & 200 & 58 & 0 & 100 & 0 & 0 \\
\hline & & 300 & 102 & 3.9 & 91.2 & 0 & 4.9 \\
\hline & Rumena golica & 200 & 234 & 0 & 100 & 0 & 0 \\
\hline & & 300 & 96 & 1.0 & 97.9 & 0 & 1.0 \\
\hline & Slovenska golica & 200 & $0^{\mathrm{z}}$ & l & l & l & / \\
\hline & & 300 & 12 & 0 & 100 & 0 & 0 \\
\hline & Turkey \#2 & 200 & 10 & 10.0 & 90.0 & 0 & 0 \\
\hline & & 300 & 72 & 1.4 & 98.6 & 0 & 0 \\
\hline \multirow[t]{4}{*}{2012} & Gleisdorfer Diamant & 200 & 202 & 0 & 98.0 & 0 & 2.0 \\
\hline & & 300 & 40 & 0 & 92.5 & 0 & 7.5 \\
\hline & GL Maximal & 200 & 207 & 0 & 99.0 & 0 & 1.0 \\
\hline & & 300 & 151 & 0.7 & 96.7 & 0 & 2.6 \\
\hline
\end{tabular}

${ }^{\mathrm{z}}$ Lost as a result of contamination during in vitro culture.

Table 5. Comparison of haploid induction efficiencies when using different Cucurbita accessions as a pollen donor and 'GL Opal' as a female parent.

\begin{tabular}{|c|c|c|c|c|c|c|}
\hline \multirow[b]{2}{*}{ Pollen donor } & \multirow{2}{*}{$\begin{array}{c}\text { Irradiation } \\
\text { dose (Gy) }\end{array}$} & \multirow{2}{*}{$\begin{array}{c}\text { Embryos } \\
\text { with ploidy } \\
\text { determined (no.) }\end{array}$} & \multicolumn{4}{|c|}{ Ploidy level (\%) } \\
\hline & & & $\mathrm{n}$ & $2 n$ & $3 n$ & $4 n$ \\
\hline \multirow[t]{2}{*}{ Yellow Long } & 200 & 139 & 0 & 97.8 & 0 & 2.2 \\
\hline & 300 & $0^{\mathrm{z}}$ & / & / & I & / \\
\hline \multirow[t]{2}{*}{ GL Maximal } & 200 & 161 & 0 & 98.1 & 0 & 1.9 \\
\hline & 300 & 106 & 0 & 97.2 & 0 & 2.8 \\
\hline \multirow[t]{2}{*}{ White Acorn } & 200 & 163 & 0 & 94.5 & 0 & 5.5 \\
\hline & 300 & 61 & 1.6 & 86.9 & 0 & 11.5 \\
\hline \multirow{2}{*}{$\begin{array}{l}\text { Muscade de } \\
\text { Provence }\end{array}$} & 200 & $0^{\mathrm{z}}$ & / & / & l & / \\
\hline & 300 & $0^{\mathrm{z}}$ & / & l & l & / \\
\hline \multirow[t]{2}{*}{ Elite F1 } & 200 & 94 & 0 & 100 & 0 & 0 \\
\hline & 300 & 123 & 0 & 97.6 & 0 & 2.4 \\
\hline
\end{tabular}

${ }^{\mathrm{z} N o}$ fruit set.

'Gleisdorfer Diamant', and 'Turkey \#2', whereas other accessions ('Beppo', 'Naked Seed', 'Rumena golica', and 'GL Maximal') exhibited a better response at 300 Gy. The irradiation doses are much lower than the doses used in melon but, as summarized by Kurtar and Balkaya (2010), Cucurbita pollen tends to rapid viability loss as a result of dehydration and radiosensitivity during irradiation. This could be attributed to its extraordinary size (180 to $200 \mu \mathrm{m})$ and morphology [12 operculated pores (Nepi and Pacini, 1993)], which is not the case in other genera of this family. These characteristics might also limit the success of haploid induction.

When studying the effect of a female parent on haploid embryo induction, differences between accessions were observed. The highest percentages of haploid embryos were found in 'Turkey \#2' (200 Gy) followed by 'Gleisdorfer Ölkürbis' (200 Gy) and 'Naked Seed' (300 Gy), with 10\%, 4.4\%, and 3.9\%, respectively, although the small sample number might have led to an overestimation of the haploid percentage in 'Turkey \#2'. One cultivar, Slovenska golica, remained unresponsive as a female parent to haploid induction; however, the number of measured embryos was the lowest among all tested accessions. Similar to our results obtained in hull-less pumpkin, Kurtar and Balkaya (2010) were able to obtain haploids only from certain accessions of Cucurbita maxima, whereas in cucumber (Claveria et al., 2005; Przyborowski and Niemirowicz-Szczytt, 1994), no significant differences among tested accessions were reported.

The effect of pollen donor on parthenogenesis has been recently studied in persian walnut [Juglans regia (Grouh et al., 2011)], in which one donor was found to be effective in all tested female parents, whereas the other only in some of them. A more detailed study was carried out in kiwifruit [Actinidia deliciosa (Pandey et al., 1990)], in which all pollen donors were found to be effective but with differences in the haploid induction efficiencies. In our experiments, only one cultivar (White Acorn) effectively induced haploids when 'GL Opal' was used as the female parent. However, 'GL Opal' used as a pollen donor was effective in all tested accessions, except 'Slovenska golica'.

Our study provides the first large-scale analysis of ploidy in putative parthenogenetic regenerants in $C$. реро. It should be noted that, although flow cytometric determination of ploidy is undoubtedly a superior technique for ploidy analysis, it is to some extent problematic in Cucurbitaceae. As shown previously in watermelon (Sari et al., 1994) and cucumber (Gilissen et al., 1993), young tissues often exhibit endoreduplication. These additional peaks (as shown in Fig. 2C) might partly obscure the presence of the first, often smaller, G1 peak representing ploidy level. We detected four ploidy levels in this study. Although the majority of the 3830 samples tested were diploid, a significant proportion was found to be tetraploid. Determination of a relatively large proportion of tetraploids was unexpected but clearly correlated with increased dose delivered to pollen grains. Searching published data, we were unable to find similar reports of induced tetraploidy in haploid induction attempts through pseudofertilization. The mechanism of the formation of tetraploids is unclear and needs further analysis; so far we can only speculate that a zygote formed by a normal egg cell and a damaged pollen nucleus is somehow directed into early genome duplications. 
Table 6. Observed allele lengths of chosen polymorphic simple sequence repeat loci in bps in tested parental hull-less pumpkin plants given by accession.

\begin{tabular}{lllll}
\hline & & \multicolumn{3}{c}{ Accession } \\
\cline { 2 - 5 } Locus $^{z}$ & Gleisdorfer Ölkürbis & Turkey \#2 & Beppo & GL Opal \\
\hline CMTp80 & $168,170,172$ & 168 & 170,172 & $168,170,172$ \\
CMTp88 & 182,192 & 182,192 & 182,192 & 182,192 \\
CMTp125 & $118,128,130$ & 130 & 118,130 & 128,130 \\
CMTp142 & $161,173,209$ & 165 & 173,183 & $165,173,183,209$ \\
CMTp235 & $146,161,170,173$ & 161,170 & 167,170 & $164,167,173$ \\
CMTp245 & 134,149 & 149 & 134,149 & 134,149 \\
\hline
\end{tabular}

${ }^{\mathrm{z}}$ Gong et al. (2008).

Finding an appropriate polymorphic codominant SSR marker specific for an accession suitable for homozygosity testing was a difficult task because of the high genetic similarity within the gene pool of hull-less pumpkin, which has previously been reported (Gong et al., 2012), and the low level of uniformity within accessions used, so a marker for individual plants and pollination combinations was required. Spontaneous chromosome doubling is generally regarded as a rare event in gynogenic haploid induction (Bohanec, 2009) and our decision to perform molecular analysis on a significant number of diploid plantlets was based on the complete absence of homozygosity studies during haploid (and DH) induction in Cucurbita sp. However, homozygosity studies of induced parthenogenetic embryos have been reported in other species of the Cucurbitaceae family. In cucumber, the authors found no spontaneously DH plants using SSR markers (Claveria et al., 2005), whereas in melon, Gonzalo et al. (2011) used SSRs and restriction fragment length polymorphism markers and found that two of 141 in vitro-rescued parthenogenetic embryos were diploid and homozygous for all the molecular markers tested. Our finding that none of the 253 tested diploid embryos could be confirmed as DH therefore contradicts the speculation of Kurtar and Balkaya (2010) that spontaneous diploidization occurs among parthenogenetic embryos of C. maxima. Our results show that the use of SSR markers is efficient, because the majority $(96.8 \%)$ of putatively parthenogenetic embryos were discriminated by the first two loci tested, whereas three were sufficient for the determination of heterozygosity of $99.6 \%$ of embryos. An interesting observation was that the paternal SSR amplicon at one of the tested markers was missing from four heterozygous plantlets, which could be the result of mutation or chromosome deletion after irradiation or segregation of a null allele at a paralogous locus.

In the presented study, a method for haploid induction in hull-less pumpkin was elaborated for the first time. We showed that, using selected polymorphic markers, homozygosity can be efficiently tested and our results suggest that there is no further need for the testing of diploid embryos because of their zygotic origin. Rigid security regulations for gamma ray facilities limit future use of a gamma source of radiation and an increased interest in X-ray treatments is anticipated (Food and Agriculture Organization of the United Nations/International Atomic Energy Agency, 2013). Also for this reason, the elaborated method might have broad applicability.

\section{Literature Cited}

Bohanec, B. 2003. Ploidy determination using flow cytometry, p. 397403. In: Maluszynski, M., K.J. Kasha, B.P. Forster, and I. Szarejko (eds.). Doubled haploid production in crop plants: A manual. Kluwer Academic Publishers, Dordrecht, The Netherlands.
Bohanec, B. 2009. Doubled haploids via gynogenesis, p. 35-46. In: Touraev, A., B.P. Forster, and S.M. Jain (eds.). Advances in haploid production in higher plants. Springer Science + Business Media, Dordrecht, The Netherlands.

Cardoso, A.I.I. 2004. Depression by inbreeding after four sucessive [sic] self-pollination squash generations. Scientia Agricola 61:224227.

Claveria, E., J. Garcia-Mas, and R. Dolcet-Sanjuan. 2005. Optimization of cucumber doubled haploid line production using in vitro rescue of in vivo induced parthenogenic embryos. J. Amer. Soc. Hort. Sci. 130:555-560.

Food and Agriculture Organization of the United Nations/International Atomic Energy Agency. 2013. Developments at the plant breeding and genetics laboratory, Seibersdorf. Plant Breeding Genet. Nwsl. $30: 27-38$.

Formisano, G., C. Roig, C. Esteras, M.R. Ercolano, F. Nuez, A.J. Monforte, and M.B. Pico. 2012. Genetic diversity of Spanish Cucurbita pepo landraces: An unexploited resource for summer squash breeding. Genet. Resources Crop Evol. 59:1169-1184.

Gilissen, L.J.W., M.J. van Staveren, J. Creemers-Molenaar, and H.A. Verhoeven. 1993. Development of polysomaty in seedlings and plants of Cucumis sativus L. Plant Sci. 91:171-179.

Godbole, M. and H.N. Murthy. 2012. Parthenogenetic haploid plants using gamma irradiated pollen in snapmelon (Cucumis melo var. momordica). Plant Cell Tissue Organ Cult. 109:167-170.

Gong, L., H.S. Paris, M.H. Nee, G. Stift, M. Pachner, J. Vollmann, and T. Lelley. 2012. Genetic relationships and evolution in Cucurbita pepo (pumpkin, squash, gourd) as revealed by simple sequence repeat polymorphisms. Theor. Appl. Genet. 124:875-891.

Gong, L., G. Stift, R. Kofler, M. Pachner, and T. Lelley. 2008. Microsatellites for the genus Cucurbita and an SSR-based genetic linkage map of Cucurbita pepo L. Theor. Appl. Genet. 117:37-48.

Gonzalo, M.J., E. Claveria, A.J. Monforte, and R. Dolcet-Sanjuan. 2011. Parthenogenic haploids in melon: Generation and molecular characterization of a doubled haploid line population. J. Amer. Soc. Hort. Sci. 136:145-154.

Grouh, M.S.H., K. Vahdati, M. Lotfi, D. Hassani, and N.P. Biranvand. 2011. Production of haploids in Persian walnut through parthenogenesis induced by gamma-irradiated pollen. J. Amer. Soc. Hort. Sci. 136:198-204.

Katoh, N., M. Hagimori, and S. Iwai. 1993. Production of haploid plants of melon by pseudofertilized ovule culture. Plant Tissue Cult. Lett. 10:60-66.

Kump, B. and B. Javornik. 1996. Evaluation of genetic variability among common buckwheat (Fagopyrum esculentum Moench) populations by RAPD markers. Plant Sci. 114:149-158.

Kurtar, E.S. and A. Balkaya. 2010. Production of in vitro haploid plants from in situ induced haploid embryos in winter squash (Cucurbita maxima Duchesne ex Lam.) via irradiated pollen. Plant Cell Tissue Organ Cult. 102:267-277.

Kurtar, E.S., A. Balkaya, M. Ozbakir, and T. Ofluoglu. 2009. Induction of haploid embryo and plant regeneration via irradiated pollen technique in pumpkin (Cucurbita moschata Duchesne ex. Poir). Afr. J. Biotechnol. 8:5944-5951. 
Kurtar, E.S., N. Sari, and K. Abak. 2002. Obtention of haploid embryos and plants through irradiated pollen technique in squash (Cucurbita pepo L.). Euphytica 127:335-344.

Nepi, M. and E. Pacini. 1993. Pollination, pollen viability and pistil receptivity in Cucurbita pepo. Ann. Bot. (Lond.) 72:527-536.

Pandey, K.K., L. Przywara, and P.M. Sanders. 1990. Induced parthenogenesis in kiwifruit (Actinidia deliciosa) through the use of lethally irradiated pollen. Euphytica 51:1-9.

Przyborowski, J. and K. Niemirowicz-Szczytt. 1994. Main factors affecting cucumber (Cucumis sativus L.) haploid embryo development and haploid plant characteristics. Plant Breed. 112:70-75.

Sari, N., K. Abak, M. Pitrat, J.C. Rode, and R. Dumas de Vaulx. 1994. Induction of parthenogenetic haploid embryos after pollination by irradiated pollen in watermelon. HortScience 29:1189-1190.

Sato, S., N. Katoh, H. Yoshida, S. Iwai, and M. Hagimori. 2000. Production of doubled haploid plants of carnation (Dianthus caryophyllus L.) by pseudofertilized ovule culture. Sci. Hort. 83:301-310.
Sauton, A. and R. Dumas De Vaulx. 1987. Obtention de plantes haploides chez le melon (Cucumis melo L.) par par gynogenese induite par pollen irradie. Agronomie 7:141-148.

Šiško, M., A. Ivančič, and B. Bohanec. 2003. Genome size analysis in the genus Cucurbita and its use for determination of interspecific hybrids obtained using the embryo-rescue technique. Plant Sci. 165: 663-669.

Stephenson, A.G., C.N. Hayes, M.H. Johannsson, and J.A. Winsor. 2001. The performance of microgametophytes is affected by inbreeding depression and hybrid vigor in the sporophytic generation. Sex. Plant Reprod. 14:77-83.

Sugiyama, K. and M. Morishita. 2000. Production of seedless watermelon using soft-x-irradiated pollen. Sci. Hort. 84:255-264.

Yahata, M., K. Yasuda, K. Nagasawa, S. Harusaki, H. Komatsu, and H. Kunitake. 2010. Production of haploid plant of 'Banpeiyu' pummelo [Citrus maxima (Burm.) Merr.] by pollination with soft x-rayirradiated pollen. J. Jpn. Soc. Hort. Sci. 79:239-245. 